\title{
Notas a una (Deprimente) Lectura del Teatro Hispanoamericano
}

La verdadera Cenicienta de la literatura hispanoamericana sigue siendo el teatro. Porque si América ha sido desde siempre 'el continente de la Poesía' y si ahora lo es de la novela, el teatro no ha alcanzado todavía esas cumbres de la fama y la madurez; se ha resignado a pasar como un género menor, a sobrevivir. (La historia de la cultura hispanoamericana nos ofrece un dato sorprendente: en el siglo $\mathrm{xIx}$, muchas capitales de América, Lima por ejemplo, veían más teatro del que ven en pleno siglo $\mathrm{xx}$. No sólo se ha producido un estancamiento, ha habido involución.) Una gran discontinuidad de esfuerzos ha afectado la existencia de una auténtica dramaturgia: también el público todavía reducido al que suele dirigirse (a veces, por incorrecto planteo de su relación con él) y la difusión casi estrictamente nacional de los autores. El carácter múltiple del fenómeno teatral ha dificultado aún su circulación: si los textos dramáticos nuevos no se conocen, peor suerte corren las puestas mismas y las actividades conexas a la vida teatral: se trabaja con la mala conciencia de un aislamiento casi total. Es significativo que en toda América Latina no haya una revista teatral realmente importante -algo equivalente, algo superior a Primer Acto, de Madrid-y que las únicas publicaciones dedicadas hoy al teatro latinoamericano en general sean la Latin American Theatre Review, una edición trilingüe de la Universidad de Kansas, y la cubana Conjunto, órgano del Comité Permanente de los Festivales Latinoamericanos de Teatro.

Recientemente, The Modern Drama Review (TDR) de la Universidad de New York, dedicó un número especial (invierno 70) al teatro latinoamericano y tuvo que explicar algunas de las dificultades que ofrecía el tema:

In the Latin America Richard Schechner visited, there is no theatre... Looking at the contents of this issue, it seems clear first of all that 
the few signs of life are in extra-theatre perfomances... The signs of death - the crushing catalogue of brutality, corruption, silence, despair one finds in even a few evenings' casual background reading - are on our cover. The reason they're on the cover, the reason they're photos of real, not theatre, events, is that they are overwhelmingly important and that theatre doesn't show them. For even when a text is about torture..., the surface meaning is subverted by clumsily borrowed forms and the revolutionary rhetoric rings false (Erika Munk: "A Repressive Theatre").

Debido a todo esto, las antologías generales y los estudios panorámicos del teatro hispanoamericano son instrumentos indispensables y ansiosamente buscados por los que quieren tener al menos una imagen aproximada a la situación de nuestra dramaturgia en español; más difícil es superar el aislamiento respecto del notable teatro brasileño, de cuyos textos hay escasísimas traducciones y cuyas revistas especializadas no se conocen fuera en absoluto. Uno de los investigadores y promotores más activos de aquel teatro es Carlos Solórzano, guatemalteco de nacimiento y mexicano de adopción, autor él mismo de una obra dramática distinguida en América Latina y en Europa. Su pasión teatral se encarna en varias actividades: la de estudioso, la de crítico, la de profesor, la de promotor escénico, la de antólogo. A él ya se debía el único manual verdaderamente confiable del Teatro latinoamericano del siglo XX (Buenos Aires, 1961; 2a. edición, México, 1964) que se haya escrito en español, y una amplia y servicial antología del Teatro bispanoamericano contemporáneo (México, 1964), que es de consulta obligada. Ahora, Solórzano complementa en cierto modo esta antología con otra dedicada al Teatro breve bispanoamericano, ${ }^{1}$ la primera recopilación que se hace de nuestra producción dramática corta de los últimos años.

Naturalmente, el teatro breve no es sino una modalidad del teatro hispanoamericano, es una limitada parte del todo. Pero si se da por cierto lo que señala Solórzano en su prólogo - que es una de las modalidades donde mejor se dan las posibilidades de sintesis y trascendencia de los medios expresivos del teatro contemporáneo-, esta selección es un buen indicio de las tendencias y búsquedas que se registran hoy en nuestra dramaturgia. La creciente importancia del teatro breve le parece a Solórzano un fenómeno propio de la postguerra y común a Europa y América: es la zona propia del experimento dramático, que juega con el tiempo, el espacio y la persona para crearles una dimensión nueva,

1 Selección, prólogo y notas de Carlos Solórzano. Madrid, Aguilar, 1970. 
fantástica o profundamente real. ¿Cómo ha resuelto el antólogo el problema de presentar una imagen orgánica de ese tipo de teatro?

La selección tiene un notorio propósito didáctico o de muestreo: no se trata ni de un grupo limitado a "los mejores" textos o autores, ni de los países teatralmente "más importantes"; es, más bien, una ordenada lista de dieciséis obras que corresponden a otros tantos países hispanoamericanos o sea casi todos. Los únicos países no representados son Honduras, Bolivia y Chile; la ausencia de los dos primeros no parece grave, pero la del tercero es inexplicable. Solórzano no debe ignorar las obras breves de Egon Wolff, de Sergio Vodanovic, de Jorge Díaz, etc.; tampoco la existencia de una recopilación del Teatro cbileno actual (Santia. go, 1966) como fuente de información directa para su trabajo. Aparte de esa saltante omisión, la antología presenta otros dos defectos menores: el prólogo es demasiado general y simplificador; las notas que preceden a cada texto pudieron incluir una bibliografía de los autores y los párrafos de comentarios crítico ser menos encomiásticos y difusos (de Francisco Tobar-García, por ejemplo, se dice que "personifica la imagen completa del hombre de teatro actual, pues sabe que los textos deben ser sometidos a la luz del escenario para determinar su vida interior definitiva" (p. 79).

\section{UNA MEDIOCRIDAD GENERAL}

En cuanto a la selección misma es evidente que Solórzano ha tenido que ser fiel con su propio criterio - un texto por país- y ser benevolente para que todos estén representados. Esa es la utilidad de la antología: más que con los gustos de Solórzano tiene que ver con la realidad que nuestro teatro of rece al estudioso. (Cabe anotar que siete de las dieciséis piezas recogidas formaron el repertorio del Primer Festival de Teatro Nuevo de Latinoamérica que se realizó en México en 1968, al que concurrió el autor y sobre el que ofreció una reseña crítica en Latin American Thedtre Review, 3/2, 1970, muy interesante para conocer una opinión más personal de Solórzano sobre aquellas obras.) Pues bien, esa realidad revela pobreza, contenidos exiguos, uso de formas ya muy superadas. Revisando la antología, uno no puede menos que deprimitse y reparar en la mediocridad de tantos textos para hacer algunas amargas reflexiones sobre este teatro hispanoamericano. Primera: el lector no latinoamericano que tenga este libro entre manos, pensará que data de 20 , quizá 30 años atrás. Los textos están llenos de ideas viejas (inclusive, algunas de las que sirven, ya son viejas), de formulaciones en proceso de oxidación, de caducas visiones de la condición humana. No se siente el espíritu fresco 
de las verdaderas innovaciones dramáticas. Todavía hacen estragos los dramones psicologistas, el idealismo superfluo, los fáciles esquemas del tema agrario o político.

Las revoluciones teatrales parecen no haber pasado para la mayoría de estos textos; en un ámbito de tan veloces cambios como el teatral, eso los coloca en una especie de prehistoria o de limbo. Segunda observación: no existe (casi no existe) un lenguaje teatral. A veces un buen argumento, una situación con posibilidades, son arruinados por un lenguaje insulso, resultado neutro de influjos varios, legibles al trasluz. Encarado sin rigor, el diálogo resulta incapaz de crear imágenes visuales y especiales: es literal, no pensado para el oído y para un tiempo de dicción. Y por último: se trata de un teatro generalmente sin audacia, tímido ante sus propios descubrimientos. No se destruyen ni se crean realmente nucvas formas; más bien se las adapta y se las usa: nuestro teatro vive una suerte de vida prestada. In el fondo, son síntomas de un solo fenómeno: inmadurez, todavía más notoria hoy que la novela hispanoamericana, por ejemplo, ha logrado tan alto nivel en un contexto internacional. Carente de actualidad, de imaginación, de originalidad, nuestro teatro no ha sabido todavía asumir los grandes asuntos que le dicta la propia realidad hispanoamericana.

Para no ser injustos con el teatro que se escribe en toda esta América, hay que señalar que el vigor y la riqueza formal del nuevo teatro brasileño, el mejor teatro social del continente, ya está fertilizando a nuestros jóvenes autores que persiguen una inmediatez entre el espectáculo y su público a través de medios como: música y bailes populares, sistemas de representación informal, uso del folklore, movimientos corales, recreación de fórmulas del teatro clásico, etc. Los síntomas de una nueva asunción del fenómeno teatral de parte de algunos autores o grupos nacionales, son todavía un tanto vagos y dispersos como para registrarlos en una antología, pero ya se dejan sentir justamente en ciertos países que habían permanecido en la periferia de los centros tradicionales de actividad teatral. Hablo de lo que conozco: en el Perú, por ejemplo, donde el teatro es desigual, muy minoritario y caótico, se pasa del más estricto provincialismo en actuación y puestas, al snobismo más estridente de los textos franceses o neoyorkinos - han surgido dramaturgos y textos realmente nuevos, en cuanto se desentienden de los moldes habituales del teatro peruano y registran los problemas de la realidad nacional o latinoamericana en un grado más profundo, más lúcido y esencialmente teatral. Uno de ellos es Alonso Alegría, cuya obra El cruce sobre el Niágara, Premio Casa de las Américas 1969, plantea, con una sencillez encantadota, nada 
menos que el problema o juego dialéctico entre el líder y la masa revolucionaria, o entre el intelectual y el trabajador, o entre la poesía y la técnica. (Esto es lo que está pasando, en los actuales momentos, en el teatro peruano; es presumible que otros movimientos subterráneos estén recorriendo la producción dramática de otros países.)

\section{UNA PIEZA ADMIRABLE}

Pero vuelvo al libro y al panorama que en ella queda fijado. Hay dos niveles o grupos de obras: uno, basiante reducido, de textos que tienen un evidente interés, pese a fallas o carencias parciales; otro, el mayor, de obras básicamente malogradas, inservibles o ilegibles. Encima de ambos grupos sólo puede colocarse una pieza admirable: Los fantoches del propio Carlos Solórzano. Representada por primera vez en 1958 y publicada en su Tres actos en 1959, la pieza contiene las preocupaciones constantes de todo su teatro: el tema de la libettad humana y la muerte tal como la plantea el existencialismo, la lucha del bien y del mal al nivel concreto de la vida social, la interpretación de los mitos y costumbres populares latinoamericanas a la luz del pensamiento humanista contemporáneo. Indígena y universal, la obra se inspira en la costumbre mexicana de la "Quema del Judas" el Sábado de Gloria, en la figura de unos muñecones grotescos que estallan con un cartucho de pólvora; aprovecha el colorido de lo folklórico y el soplo auténtico de las tradiciones primitivas, pero eleva todo a otra dimensión, lo potencia como una alegoría filosófica - los muñecos somos nosotros los hombres, el Viejo que hace los muñecos es Dios - que plantea la muerte como la única libertad concedida a la condición humana: somos para no ser, ésa es la terrible imagen que concreta cl juego de estos fantoches, absurdos y vacíos mientras viven su vida inerte de muñecos, gloriosamente humanos sólo cuando estallan en el aire de la fiesta por elección del Viejo mudo y ciego que los fabrica. Uno de los fantoches implora algún sentido para sí mismo, algo de piedad de parte del Viejo hacia sus criaturas:

He visto morir a muchos jóvenes y siempre me ha causado horror. Pon una nueva medida a tu ministerio, un poco de lógica... ¿ $\mathrm{O}$ no puedes? ¿O lo que quieres es que nunca estemos satisfechos de nada? ¿Tú mismo estás satisfecho? Responde una vez, una sola vez. (p. 340).

El Artista, en cambio, no pretende la bondad divina: reclama la dig. nidad humana ante la muerte: 
Si ése ha de ser nuestro fin, vamos a juntarnos todos, acerquemos a nosotros una cosa encendida y volaremos por el aire en un solo estallido, como una bomba gigantesca, y todos esos como nosotros a quienes el viejo no ha puesto aún el terrible cartucho en el centro del cuerpo, y mis rayas de colores, y tus papeles, y tus vestidos de picos... Tal vez ... es la única libertad que podemos desear (p. 336).

La escena final -el dedo de la Niña, que elige al azar en nombre del Viejo, apunta ominosamente hacia la platea, hacia los fantoches y somos nosotros- resume esa imagen con fuerza aleccionadora. Con Los fantoches, Solórzano logra una no desdeñable proeza: desarrollar una visión profundamente existencialista de la vida a través de una fábula sencilla sacada de la tradición latinoamericana, sin que aquélla parezca sobreimpuesta ni esté desfigurada; ha obtenido, pues, una pequeña obra de arte.

\section{DOS MERITORIAS}

Del grupo de obras que por algún motivo se destacan en el conjunto, las que me parecen más meritorias son: Las pinzas del venezolano Román Chalbaud, y La señora en su balcón de la mexicana Elena Garro. Las pinzas es una muy lograda versión latinoamericana del teatro del absurdo: las huellas de Genet y Arrabal (con alguna dosis del teatro de la crueldad) son perceptibles en esta obra de diálogo muy exacto e incisivo, planteada con un rigor casi geométrico y un humor seco, implacable. (Es interesante anotar que la pieza fue escrita como parte de una experiencia bastante singular de producción dramática: tres autores acordaron escribir tres obras diferentes a partir de unas líneas iniciales comunes; las obras se presentaron en un espectáculo conjunto titulado Triángulo.) Al manejar con autoridad una serie de motivos ya manejados por la vanguardia - la identidad perdida o multiplicada, la loca fascinación por el crimen y el castigo, el sentido ceremonial de las encarnaciones, el aire perverso de todo el juego-, Chalbaud revela una mano dramática hábil y, sobre todo; bien controlada. Elena Garro es casi una especialista del género teatral breve y de los temas del hogar y la vida conyugal en una clave siempre poética. La técnica de La señora en su balcón es sencilla pero eficaz: tres instantes en la vida frustrada de una mujer - sus 8, 20 y 40 años- son evocados desde el filo de sus actuales 50 y presentados como otras tántas personificaciones de la misma Clara que sostienen diálogo con ella en una inquietante negación del tiempo y espacio reales: 
la dimensión de la pieza es mental, psicológica -si no psicótica. El tono de buen drama de sentimientos es celosamente mantenido a lo largo de la pieza (salvo algún recodo donde el lirismo se excede y se malogra por culpa de una retórica seudopoética: "me importa sólo ver el rosa de tus encías, oir el ritmo de tambores de tus pasos, la música geométrica de tu falda, el golpe marino de tu garganta, único puerto en donde puedo anclar" (p. 352), pero la verdadera tragedia estalla en las últimas líneas, en ese final brutal y grotesco: el suicidio de Clara comentado en el habla popular y cruel del lechero que llega y que encharca la belleza necesaria del sacrificio en una mera crónica policial.

\section{VIRTUDES Y PROBLEMAS}

Pueden sumarse al grupo escogido otras tres obras que mencionaré sin establecer entre ellas precedencia alguna. Historia del bombre que se convirtió en perro, del argentino Osvaldo Dragún, es una de las conocidísimas Tres historias para ser contadas, uno de los caballitos de batalla de los grupos teatrales juveniles de América, por la facilidad de su montaje y de su fábula. La pieza fue estrenada en 1957; el tiempo no pasa en vano para el teatro y tampoco para esta obra ( $o$, por lo menos, para esta Historia), que ahora parece frágil, leve, superficial, ya demasiado candorosa. Sin embargo, todavía funciona a cierto nivel visual, físico, diría: es un ejercicio corporal e imaginativo bastante provechoso. No conozco la obra dramática del ecuatoriano Francisco Tobar-García, salvo ésta, Las sobras para el gusano, pero basta para mostrar en él a un dramaturgo ambicioso, que usa recursos complicados y plurales, que parece (un poco a destiempo) un discípulo aprovechado y aparatoso de los densos dramas de O'Neil. Las ideas básicas del texto - los personajes presentados simultáneamente en distintas etapas de su vida, el pasado colándose intensamente en el presente, la interiorización del tiempo teatral, etc. lo aproxima en cierto sentido a $L a$ señora en su balcón de Elena Garro. Pero Tobar-Garcia va más allá, sin temerle a la desmesura y la tremebundez; "la pieza debe ser presentada en un clima de auténtica pesadilla", advierte, y en otra parte, "la obra... tiene un carácter de alucinación" (p. 82). Para ellos multiplica los personajes, propone un escenario lúgubre con casa abandonada $\mathrm{y}$ ventanas chirriantes, subraya un clima luctuoso y obsesivo. En verdad, el autor maneja esos materiales con una solvencia considerable y con un efecto convincente. Pero la gratuidad de la empresa se revela al final, cuando se advierte que ha convocado recursos e imágenes sin tener nada muy importante que decir; la 
empresa es un notable esfuerzo en el vacío. Estudio en blanco y negro no hace mucha justicia a la importante obra dramática del cubáno Virgilio Piñera. Está bien hecha, el diálogo suele ser feliz, pero es de una minoridad irrecusable. Quizá su mayor mérito sea el construir alrededor de una situación trivial, de un no-suceso, un delicado juego erótico.

\section{LOS FRACASOS}

El resto - nueve piezas del total de dieciséis- ya es en general teatro del malo. Siguiendo el orden de la antología: $E l$ apuntador del uruguayo Carlos Maggi intenta montar una comedia jocosa sobre una estructura algo pirandeliana (los personajes conversan sobre sí mismos y el autor, el escenario está visto desde atrás). Casi todo el intento está echado a perder (hay que reconocer que la última escena de Bruno, con su monólogo sobre la vida y la muerte, p. 40, tiene intensidad) por una permanente confusión entre el humor y el chiste, entre lo popular y lo convencional. Frases como "Y si nos fuéramos al Polo con varias frazadas eléctricas y un solo piyama; pero de dos plazas... el piyama?" o "Renuncio a tu estado civil; lo que yo busco contigo es un estado de sitio" (p. 31) son frecuentes en el texto. Peor - por melodramática, por primaria, por falsa- es Historia de un numero de la paraguaya Josefina Plá, escritora tan valiosa en cambio como crítico. Esta alegoria del individuo y la masa está plagada de clisés y de ingredientes truculentos; en la escena final, por ejemplo, al pobre hombre anónimo lo juzgan, le colocan un traje a rayas $\mathrm{y}$, además, el número 131313 , para que no queda duda de que es un desgraciado. Gustavo Andrade Rivera representa a Colombia y, después de leer su Remington 22, uno se pregunta por qué Solórzano lo prefirió a él y no a Enrique Buenaventura, que tiene algunas piezas breves valiosas y que sigue representando lo mejor del teatro colombiano. Andrade Rivera se pregunta: "¿Cómo escribir sobre lo que pasa en Colombia sin caer en el sectarismo? ¿Sin caer, sobre todo, en el novelón, si es novela, o en el dramón, si es cosa de teatro?" (p. 143), pregunta razonable porque su tema es la violencia política. Increíblemente, su solución - no crear personajes, sino lo que llama "muñecos"- es de un maniqueísmo insoportable. ;Y a qué distancia están sus "muñecos" de los "fantoches" de Solórzano? La pieza chapotea en un mar de demagogia, de ideas preconcebidas y de una irrelevancia general para dar una versión dramática de la violencia colombiana. Por otro lado, nadie sabe bien por qué, el autor aprovecha las indicaciones escénicas para hacer bromas o para criticar cosas ajenas a la obra: "Es blanco porque va de 
blanco, por oposición al negro, que va de negro" (p. 159); "Reina de la Nueva Ola es un engendro de nadaísmo, constructivismo, existencialismo, nuevaolismo; de todas estas mujercitas, medio prostitutas, medio intelectuales, que pasean por el mundo sus desengaños físicos y sus noes espiri.uales" (p. 161).

El portorriqueño Francisco Arriví, en cambio, no parece inhábil ni desconocedor del oficio teatral; el problema es que apunta sumamente bajo; al melodrama doméstico y al sentimentalismo. Es un artesano a lo Paso, a lo Mihura, que, de pronto, como ocurre en Un cuento de badas, teje bien un cuadro (el tercero). La Fábula de los cinco caminantes, del dominicano Iván García, es un ejemplo penoso de vaciedad creadora y de tediosa charlatanería. Es a nivel verbal donde el fracaso de García se hace más evidente: para desarrollar un tema popular, el autor adopta un lenguaje construido palabra sobre palabra, tan reiterativo que la lectura se hace soporífera. Todo es previsible y aburrido; los esdrújulos y los lugares comunes comienzan desde los nombres de los personajes (Fórtido, Mínimo, Orátulo, Revóluto y Cárnido: nạda se deja a la imaginación). Cárnido recomienda: "Basta de palabras" (p. 222), pero García no le hace caso, y las acumula sin descanso para hacer charadas tontas ("verdadera conjunción de disonancias desordenadas colocadas en perfecto orden", p. 215; "El tiempo es oro, y el oro es oro", p. 222), para subrayar cualquier cosa ("Lo he dicho y lo repito: no pasarán, no pasarán, no pasarán, no pasarán..."; "Pega, pega, pega"; "Aleluya, aleluya, aleluya, aleluya, aleluya...", todo en la misma página 223); más bien parece seguir el consejo de Revóluto: "Palabras y palabras. No me quiten las palabras" (ibid.) En manos de otro autor, quizá la idea de Segundo asalto, del panameño José de Jesús Martínez, habría servido para algo; él no hace más que arruinarla con una gran pobreza expresiva y con un desorden expositivo que no crea ninguna situación válida. La ingenuidad de algunas escenas es irritante:

EL.-Bien, maestra. Preséntame tu mundo.

ELLA.-Mundo; te presento a mi amigo. Es torpe como un ciego, malvado como un niño (p. 255).

Más cándida y torpe es Algo más que dos sueños, del costarricense Alberto Cañas, un drama amoroso que intenta confrontar los planos del sueño y la realidad; lo que logra es un melodrama dulzón y lacrimoso, con divagaciones e idealismos tan vanos como:

ISABEL.-Y recordar. . ¿ ino es una manera de amar?

ANTONIO.-No, Isabel. Recordar es sólo recordar. No es resucitar. 
ISABEL.-Sí, es posible, Antonio. No es resucitar. (Pausa). Es como la poesía. Cuando la poesía evoca un jardín o un amor, aquello no es el amor ni es el jardín; sin embargo, se siente como si lo fueran. Tú has sentido como si tu recuerdo fuera otra vez nuestro amor, pero no lo era (p. 278-79).

Como se ve, Historia de un número, Un cuento de badas y Algo más que dos sueños son, especialmente, modelos de las formas envejecidas que todavía circulan en nuestro teatro de pretensiones artísticas.

El nicaragüense Alberto Icaza, el más joven de todos los autores, es director de escena; su ficha personal parece indicar que Ancestral 66 es su única obra (¿escrita a los 21 ?), lo que debe tenerse en cuenta a su favor. Aunque es un texto demasiado tremendista, que confía mucho en los artificios espectaculares, hay un ocasional buen uso dramático de los elementos legendarios y mágicos del mundo maya, que chocan violentamente con la actualidad nicaragüense. Le sobran muchas escenas y hay bastante confusión de propósitos, pero es más perdonable que algunas de las anteriores. Por último, del salvadoreño Alvaro Menén Desleal se presentan $E l$ circo, "picza en tres movimientos y un allegro fúnebre para gran finale", y otras tres piezas brevísimas. Se trata de non-sense plays, piruetas y acrobacias absurdas, textos al nivel de los sonidos puros y el hermetismo cómico (el diálogo es en silencio, las palabras son números). Sin humor y sutileza suficientes, estas experiencias suelen resultar bastante aburridas; Menén Desleal no hace precisamente derroche de aquéllos y el lector puede muy bien prescindir de ellas: no dicen nada que valga la pena.

FINAL

Igual que al terminar la lectura de la Antología, al poner punto final a este largo comentario crítico del libro, una misma impresión me acompaña; la de encontrar a un reducido grupo de autores que lucha por dar modernidad, hondura, verdad, a un teatro esclerosado y caduco, herencia que se resiste a desaparecer en medio de los signos de cambio. La pregunta por ahora sin respuesta es: ¿bastará ese puñado de autores para fundar el teatro hispanoamericano, para acercarlo a la madurez que hoy no alcanza? La presente Antología siembra esa útil inquietud.

José Miguel Oviedo 